\title{
Predictability of drug expenditures: an application using morbidity
}

\section{data}

\section{Manuel García-Goñi}

Universidad Complutense de Madrid

\section{Pere Ibern}

Universitat Pompeu Fabra

September 27, 2006

Address for correspondence: Manuel García Goñi, Universidad Complutense de Madrid, Departamento de Economía Aplicada II. Campus de Somosaguas. 28223 Pozuelo de Alarcón (Madrid). Email: mggoni@ccee.ucm.es Tel +34913942455 Fax +34913942457.

This research was supported by an unrestricted educational grant awarded jointly to the Universities Carlos III de Madrid and Pompeu Fabra of Barcelona by The Merck Foundation, the philanthropic arm of Merck Co. Inc., White House Station, New Jersey, USA. Manuel García-Goñi also received support from project SEJ2004-01959 (Ministry of Science and Technology, Spain).

\section{Acknowledgements:}

Jordi Coderch, Josep M. Inoriza and Jordi Calsina from Serveis de Salut Integrats del Baix Empordà have supported this research with data and analysis. Norbert Goldfield and Jon Eisenlander from 3M Health Information Systems have contributed to the classification. We also thank Ricardo Mora, Pedro Albarrán, participants at seminar at Universidad Carlos III de Madrid and at AES Annual Meeting, and two anonymous referees for their helpful comments.

Keywords: drug expenditure, risk-adjustment, morbidity, clinical risk groups. 


\begin{abstract}
The growth of pharmaceutical expenditure and its prediction is a major concern for policy makers and health care managers. This paper explores different predictive models to estimate future drug expenses, using demographic and morbidity individual information from an integrated healthcare delivery organization in Catalonia for years 2002 and 2003. The morbidity information consists of codified health encounters grouped through the Clinical Risk Groups (CRGs). We estimate pharmaceutical costs using several model specifications, and CRGs as risk adjusters, providing an alternative way of obtaining high predictive power comparable to other estimations of drug expenditures in the literature. These results have clear implications for the use of risk adjustment and CRGs in setting the premiums for pharmaceutical benefits.
\end{abstract}




\section{Introduction}

The growth of pharmaceutical expenditures is a current major concern for health policy makers in Spain. There, drug expenditures have grown in the last decade to represent around $23 \%$ of total health expenditures in 2004 [1]. As a consequence, the policy agenda is focused on how these increasing expenditures should be financed and consider issues like copayment, how to selectively finance medicines, or introducing price competition in generic drugs [2]. This paper proposes risk adjustment as a tool for predicting drug expenditures and for setting the premiums for pharmaceutical benefits using individual data. We apply several specifications for the estimation beyond the usual linear specification and compare our predictability results with others from the literature.

The analysis of pharmaceutical consumption should start with information about what is prescribed and for which pathology, what is consumed and how much it costs at individual level. In order to establish a relationship between pharmaceutical consumption and morbidity, we need two essential sources: individual information about pharmaceutical costs and morbidity. Up to now, these sources have been difficult to get and therefore, the debate has focused on averages and growth rates, providing little information to take decisions at policy and management level [3].

Although several studies have used pharmacy data to predict total health care costs $[4,5,6,7,8,9]$, only a few have addressed the issue of predictability of drug spending. A feasible explanation is that usually private insurers do not offer free standing drug benefits, and public programs offering those benefits have not developed private riskbased contracts [10]. Using only demographic information and past cost, two studies in 
the 1990s [11,12] showed the highly persistent behavior of drug expenditures and the low predictive power of using only demographic information (from $R^{2}=0.02$ to $R^{2}=0.04$ ). Adding health status (morbidity) information through the diagnosis cost group/hierarchical condition category (DCG/HCC) risk-adjustment methodology $[10,13]$, different prospective models obtain higher predicting power with an $\mathrm{R}^{2}$ between 0.10 and 0.24 , while adding lag expenditures raised it to 0.55 [10]. Lastly, Pharmacy Categories (Rx-Groups) have also been used to predict pharmacy costs [13] obtaining an $R^{2}$ near 0.50 , and therefore explaining almost half of the variation of the cost in the subsequent year.

This paper fits in the literature predicting drug expenditures using a classification system for health status that allows to understand population morbidity [14,15]. We apply the Clinical Risk Groups (CRGs) classification system, which allows classifying individuals in mutually exclusive categories attending to their clinical conditions. It differs from the DCG/HCC methodology, that allows multiples categories for each individual. The CRG methodology uses information from the encounters between the health system and the patients, and allocates a severity level to each patient [16]. The uniqueness of the CRGs compared to other methods is that it supports clinical meaningfulness, the severity levels and its multiple applications.

In this paper, we link pharmaceutical consumption (outpatient, specialist, and hospital) and the morbidity in a publicly funded healthcare system environment using CRGs as a risk adjustment system. In our estimations we use three different specifications. Then we test the predictive power of our different models and compare our results to others in the literature. Finally, as a policy implication and based on our findings, we advocate the use of risk adjustment in setting the premiums for pharmaceutical benefits. 


\section{Data}

We utilize individual demographic (age and sex) and morbidity data in year 2002 and pharmaceutical expenditures in 2002 and 2003 from 87,691 individuals belonging to the Serveis de Salut Integrats Baix Empordà (SSIBE), an integrated health care delivery organization in Catalonia, Spain. For inpatient services, population covered by the integrated delivery system can use the only hospital in the county - Palamós Hospital -, while for outpatient services there are five different primary care areas. In our analysis we use primary care, specialized care, and inpatient consumption of pharmaceuticals for all individuals belonging to four primary care areas: Palamós, Torroella, la Bisbal and Palafrugell. In 2002 there were 52,916 individuals (60.35\% of population) with nonzero drug expenditures, consuming 1,206,008 prescriptions worth a total $15,124,842$ euros, including public funding (CatSalut), out-of-pocket payment (copayment), and hospital consumption. The fifth primary care area - Sant Feliu de Guíxols - is out of the analysis because of incomplete data.

The database contains 1,241,127 procedures and diagnostic codes for year 2002. Every encounter between individuals and the organization is identified, registered, and coded using ICD-9-CM (The International Classification of Diseases, 9th Revision, Clinical Modification), allowing the allocation of pharmacy costs by individuals. The CRG grouping assigns one CRG category to each patient. We use the maximum level of aggregation allowed by the CRG classification system, collecting morbidity in 9 different patient groups. Table 1 shows the demographic characteristics of the population and the composition of the $9 \mathrm{CRG}$ categories. The CRG system assigns one level of severity to each patient within the CRG category, so that in our database 
individuals are classified in 37 different risk groups (ACRG3), while the grouper allocates to 1081 groups at a more disaggregated level.

\section{Estimation Methods}

This paper estimates different models in order to predict drug expenditures in the subsequent year. Our objective is to examine the predictive properties of different models which use different information and how well they explain future cost. The basic model is characterized by:

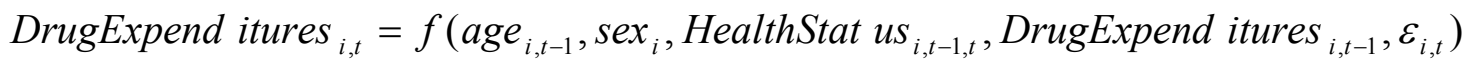

Thus, drug expenditures in year $t$ for individual $i$ are explained by some independent variables or risk adjusters. Model 1 uses only demographic information (age and sex). Model 2 considers also information on drug expenditures incurred by the individual last year $(t-1)$. Model 3 uses only prospective information on health status in previous year ( $t-1)$ provided by the CRG classification system. Model 4 is a prospective model using both demographic and health status information in previous year. Models 5 and 6 are concurrent models analogous to models 3 and 4. Thus, model 5 uses only health status information in year $t$ in order to explain drug expenditures in year $t$, and model 6 uses also demographic information.

The typical specification in the risk adjustment literature is a simple specification, in which individuals are assigned to, say, age-sex cells. This specification is nonparametric in the sense that the parameters of the expectation conditional on age and sex are of free variation. In this paper we also consider two other specifications: a "parametric" specification in which the sex and age of each individual enter as independent variables 
in a nonlinear specification (sex, age, age ${ }^{2}$, age $^{3}$, age $^{4}$ ); and a more flexible parametric specification which, for convenience, can be termed as "flexible-parametric", in which interactions between age and sex are explored in a nonlinear way (age, age ${ }^{2}$, age $^{3}$, age $^{4}$, sex*age, sex*age ${ }^{2}$, sex $^{*}$ age $^{3}$, sex $^{*}$ age $\left.^{4}\right)$. Our dependent variable, drug expenditures, is a censored variable (DrugExpenditures $\geq 0$ ) with a large number of zeros $(39.65 \%)$. Therefore, besides of using OLS, we also run a tobit estimation in our different model specifications.

The main indicator we use in order to measure how well the different model predicts is the $R^{2}$ that measures the proportion of the variation of future costs that the model predicts. Another indicator widely used is the Predictive Ratio $(P R)[17,18,19]$, which is the ratio of predicted cost to actual cost within a group of individuals of interest. If the predictive ratio is very close to one, the model predicts well for that group of individuals. If $P R<1$, the model underpredicts for those individuals, and if $P R>1$, it overpredicts. We randomly divide the population in two subsets: the estimation sample and the validation sample. We obtain the predictive models from the estimation sample and calculate the $P R$ for the validation sample for individuals of different demographic cells (age and sex) and for individuals belonging to different CRG categories.

Lastly, we provide a third indicator, Validated- $R^{2}\left(\widetilde{R}^{2}\right)$, obtained using the predicted model from the estimation sample in the validation sample, and calculating the ratio of the sum of squares explained by that predicted model to the ratio of total sum of squares in the validating sample.

\section{Results}


Table 2 shows the $R^{2}$ and the Validated- $R^{2}\left(\widetilde{R}^{2}\right)$ for the different predictive models analyzed under our different model specifications for both, OLS and tobit estimations. The proportion of explained variance increases with the quality of information used in the model. With respect to prospective models, model 1 (only demographic information) presents an $R^{2}$ close to $9 \%$, while in the case of model 3, with only health status information through the CRG classification system, it is of $21 \%$. When demographic and CRG information are combined (model 4), the proportion of explained variance is around $24 \%$. In concurrent models, the same relationship is obtained with higher predictive power, improving the $R^{2}$ from around $30 \%$ using only CRG information (model 5) to $32 \%$ when demographic information is added (model 6). Although the normal use of risk adjustment is restricted to OLS linear nonparametric estimations, we have considered two more flexible alternative specifications, "parametric" and "flexible-parametric", in order to evaluate whether the role of demographic characteristics and its interaction and clinical conditions could be better explored. However, we have found very similar $R^{2}$ in the three specifications, meaning that with only demographic and CRG information, "nonparametric" models work as well as "parametric" or "flexible-parametric" models, being simpler to interpret and use. Estimations from "nonparametric" models are very precise; and given the low correlation between age and sex, we obtain consistent and robust estimators. We also tried another "flexible-parametric" specification using the interaction of age and clinical conditions (CRG) but results were not improved. The $\widetilde{R}^{2}$ obtained for the validating sample from predictions in the estimation sample are normally slightly lower but follow the same pattern than the $R^{2}$ reported, validating the results. Tobit estimations obtained 
in general a lower $R^{2}$ than OLS models, although they predict better drug expenditures for non users.

Table 3 shows the Predictive Ratio ( $P R$ ) calculated for the different prospective models and for different groups of individuals, by clinical conditions and by age and sex. The demographic models overpredict drug expenditures for healthy individuals while underpredict those expenditures for the rest. Models using CRG information obtain PR very close to 1 for the different groups by clinical conditions, but model 4 , using also demographic information also obtains very close to 1 PR for the different demographic groups, being specially good for predicting drug expenditure of healthy individuals $(P R=0.99)$ or for female older than $80(P R=0.99)$.

Thus, adding diagnostic information through the CRG classification system from only demographic information in our sample obtains similar results than adding that information through $\mathrm{HCC} / \mathrm{DCG}$ in other samples as has been shown in the literature until a maximum $R^{2}$ of $0.24[10,13]$ in prospective models and with a higher $R^{2}$ of 0.66 in the case of concurrent models. Therefore, the CRG classification system has shown in this sample of individual data to be an alternative to other classification systems as the HCC/DCG in order to predict drug expenditures

\section{Conclusions}

The growth of pharmaceutical expenditure has created a need to improve its prediction in order to set appropriate budgets. In this paper we present the Clinical Risk Group classifications system (mutually exclusive categories providing individual clinical conditions and severity level) as an alternative to other morbidity classifications systems. Our results present CRGs as a risk adjuster with similar predicting power for 
drug expenditures to other methods in prospective models and some higher proportion of variance explained in concurrent models. Provided the predictive power, the use of prospective risk adjustment is recommended in setting premiums for pharmaceutical benefits or in setting a budget constraint of public expenditures taking into account the characteristics or risks of the covered population. As a next step, once premiums and budgets are set adjusted to population characteristics and risks, risk adjustment is potentially profitable as a tool for controlling the drug expenditure and providing incentives for efficiency in the use of pharmaceutical benefits. 


\section{References}

1. OECD Health Data. 2006.

2. Puig-Junoy J. Incentives and pharmaceutical reimbursement reforms in Spain. Health Policy 2004; 67:149-165.

3. García-Sempere A, Peiró S. Gasto farmacéutico en atención primaria: variables asociadas y asignación de presupuestos de farmacia por zonas de salud. Gaceta Sanitaria $2001 ; 15: 32-40$.

4. Sales AE, Liu CF, Sloan KL, Malkin J, Fishman PA, Rosen AK, Loveland S, Paul Nichol W, Suzuki NT, Perrin E, Sharp ND, Todd-Stenberg J. Predicting costs of care using a pharmacy-based measure risk adjustment in a veteran population. Medical Care 2003; 41(6):753-60.

5. Fishman PA, Goodman MJ, Hornbrook MC, Meenan RT, Bachman DJ, O'Keeffe Rosetti MC. Risk adjustment using automated ambulatory pharmacy data: the RxRisk model. Medical Care 2003; 41(1):84-99.

6. Zhao Y, Ellis RP, Ash AS, Calabrese D, Ayanian JZ, Slaughter JP, Weyuker L, Bowen B. Measuring population health risks using inpatient diagnoses and outpatient pharmacy data. Health Services Research 2001; $36(6$ Pt 2):180-93.

7. Lamers LM. Pharmacy Costs Groups: a risk-adjuster for capitation payment based on the use of prescribed drugs. Medical Care 1999; 37:824-830. 
8. Lamers LM, van Vliet RC. The Pharmacy-based Cost Group model: validating and adjusting the classification of medications for chronic conditions to the Dutch situation. Health Policy 2004; 68(1):113-21.

9. Powers CA, Meyer CM, Roebuck MC, Vaziri B. Predictive Modeling of Total Healthcare Costs Using Pharmacy Claims Data A Comparison of Alternative Econometric Cost Modeling Techniques. Medical Care 2005; 43(11):1065-1072.

10. Wrobel MV, Doshi J, Stuart BC, Briesacher B. Predictability of prescription drug expenditures for Medicare beneficiaries. Health Care Financing Review 2003 Winter; 25(2):37-46.

11. Coulson N, Stuart B. Persistence in the Use of Pharmaceuticals by the Elderly: Evidence from Annual Claims. Journal of Health Economics 1992; 11(3):315328.

12. Stuart B, Ahern E, Rabatin V, Johnson L. Patterns of Outpatient Prescription drug use among the elderly: evidence from the PACE program. Health Care Financing Review 1991 Spring; 12(3):61-72.

13. Zhao Y, Ash AS, Ellis RP, Ayanian JZ, Pope GC, Bowen B, Weyuker L. Predicting pharmacy costs and other medical costs using diagnoses and drug claims. Medical Care 2005; 43(1):34-43.

14. Van de Ven W, Ellis RP. Risk adjustment in competitive health plan markets. In: Culyer AJ, and Newhouse, JP, ed. Handbook in Health Economics. Amsterdam: Elsevier, 2000:755-845. 
15. Rakovski C, Loveland, SA, Anderson JJ, Berlowitz DR, Ash A. Evaluation of Diagnosis-Based Risk Adjustment Among Specific Subgroups: Can Existing Adjusters be Improved by Simple Modifications? Health Services and Outcomes Research Methodology 2002; 3:57-73.

16. Hughes JS, Averill RF, Eisenhandler J, Goldfield NI, Muldoon J, Neff JM, Gay JC. Clinical Risk Groups (CRGs). A classification System for Risk-Adjusted Capitation-Based Payment and Health Care Management. Med Care 2004; 42:81-90.

17. Ash AS, Ellis RP, Pope GC, Ayanian JZ, Bates DW, Burstin H, Iezzoni LI, MacKay E, Yu W. Using diagnoses to describe populations and predict costs. Health Care Financing Review 2000; 21:7-28.

18. Ash AS, Byrne-Logan S. How well do models work? Predicting health care costs. Proceedings of the Section on Statistics in Epidemiology of the American Statistical Association, Dallas, 1998.

19. Cumming RB, Knutson D, Cameron BA, Derrick B. A comparative analysis of claims-based methods of health risk assessment for commercial populations. Final report to the Society of Actuaries. 2002. 
Table 1: Demographic characteristics of the population. $\mathrm{N}=87691$ individuals.

\begin{tabular}{|l|r|}
\hline Demographic characteristics & \\
\hline Female & $50,07 \%$ \\
Male & $49,93 \%$ \\
& \\
Age (mean) & 41,48 \\
0 to 14 & $13,50 \%$ \\
15 to 29 & $20,49 \%$ \\
30 to 44 & $24,72 \%$ \\
45 to 64 & $21,56 \%$ \\
65 to 79 & $13,07 \%$ \\
80 or older & $6,66 \%$ \\
& \\
Aggregated Clinical Risk Group categories of patients & \\
Healthy & $72,73 \%$ \\
History of Significant Acute Disease & $6,49 \%$ \\
Single Minor Chronic Disease & $5,61 \%$ \\
Minor Chronic Disease in Multiple Organ Systems & $0,82 \%$ \\
Single Dominant or Moderate Chronic Disease & $9,78 \%$ \\
Disease in Chronic Multiple Organ Systems & $3,75 \%$ \\
Dominant Chronic Disease in Three or More Organ Systems & $0,26 \%$ \\
Dominant and Metastatic Malignancies & $0,40 \%$ \\
Catastrophic Conditions & $0,15 \%$ \\
& \\
\hline & \\
Total drug expenditures in 2002 $€$ (mean) & 162,24 \\
(Std. Deviation) & 544,4 \\
Total drug expenditures in 2003 $€$ (mean) & 187,67 \\
(Std. Deviation) & 656,4 \\
\hline
\end{tabular}


Table 2: : $R^{2}$ and $\widetilde{R}^{2}$ obtained from the different predictive models

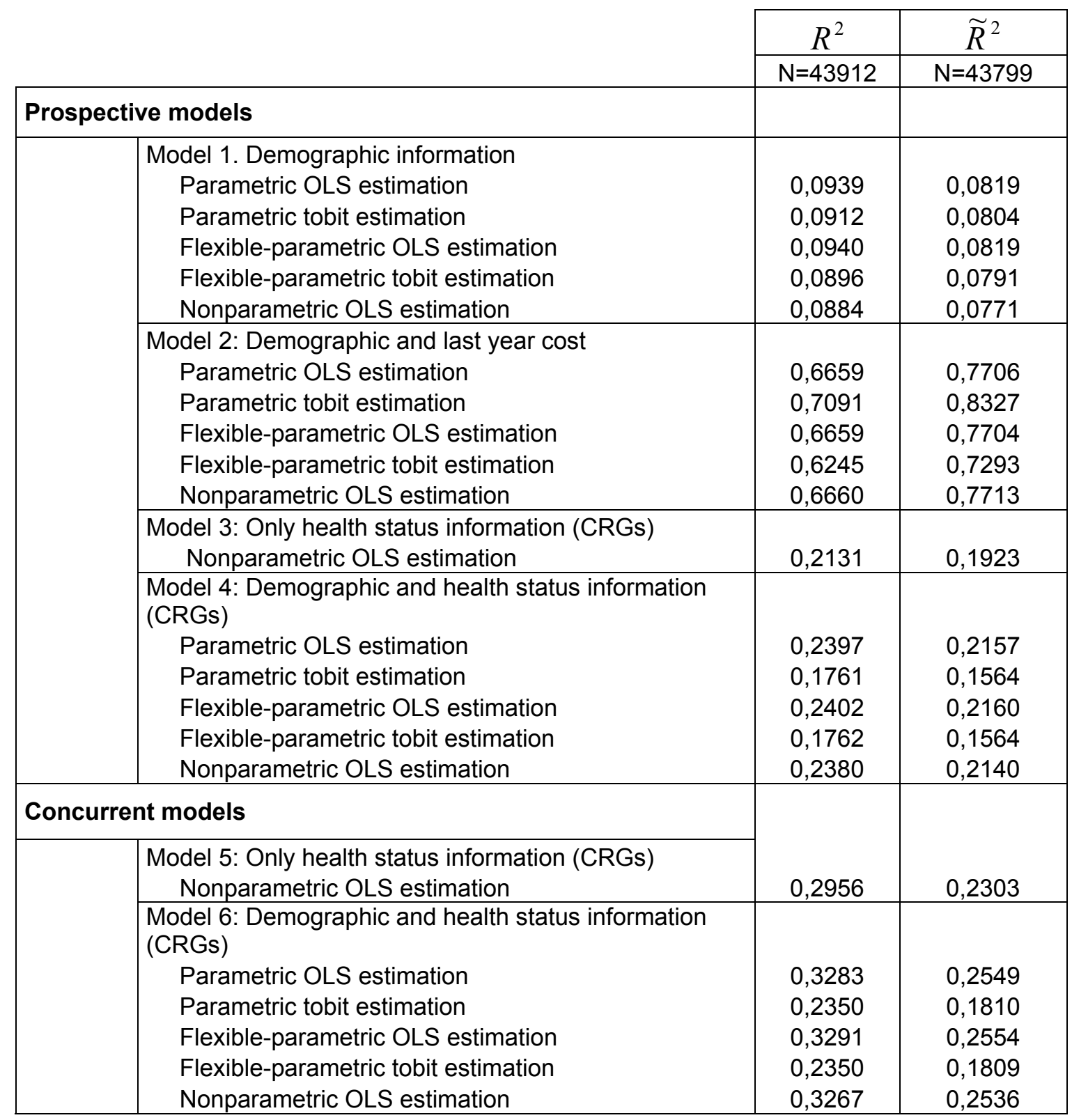


Table 3: Predictive Ratios for the different prospective models in the OLS estimation

\begin{tabular}{|c|c|c|c|c|c|c|c|c|c|c|c|}
\hline & \multirow[b]{2}{*}{$\mathrm{N}$} & \multicolumn{3}{|c|}{ Model 1. Demographic information } & \multicolumn{3}{|c|}{$\begin{array}{c}\text { Model 2: Demographic and last } \\
\text { year cost }\end{array}$} & \multirow{2}{*}{$\begin{array}{c}\text { Model 3: } \\
\text { health status } \\
\text { information } \\
\text { (CRGs) } \\
\text { Non- } \\
\text { Parametric }\end{array}$} & \multicolumn{3}{|c|}{$\begin{array}{l}\text { Model 4: Demographic and health } \\
\text { status information (CRGs) }\end{array}$} \\
\hline & & Parametric & $\begin{array}{c}\text { Flexible- } \\
\text { Parametric }\end{array}$ & $\begin{array}{c}\text { Non- } \\
\text { Parametric }\end{array}$ & Parametric & $\begin{array}{c}\text { Flexible- } \\
\text { Parametric }\end{array}$ & $\begin{array}{c}\text { Non- } \\
\text { Parametric }\end{array}$ & & Parametric & $\begin{array}{c}\text { Flexible- } \\
\text { Parametric }\end{array}$ & $\begin{array}{c}\text { Non- } \\
\text { Parametric }\end{array}$ \\
\hline total & \begin{tabular}{|l|}
43779 \\
\end{tabular} & 0,9902 & 0,9919 & 1,0000 & 1,0012 & 1,0014 & 1,0000 & 1,0000 & 1,0042 & 1,0049 & 1,0009 \\
\hline Healthy & 31838 & 1,9476 & 1,9509 & 1,9789 & 1,0816 & 1,0825 & 1,0863 & 1,0041 & 0,9959 & 0,9939 & 0,9906 \\
\hline History of Significant Acute Disease & 2845 & 0,8418 & 0,8453 & 0,8631 & 0,9225 & 0,9235 & 0,9260 & 0,7252 & 0,7174 & 0,7190 & 0,7230 \\
\hline Single Minor Chronic Disease & 2458 & 0,8559 & 0,8628 & 0,8502 & 1,0094 & 1,0112 & 1,0092 & 1,0292 & 1,0275 & 1,0278 & 1,0303 \\
\hline $\begin{array}{c}\text { Minor Chronic Disease in Multiple } \\
\text { Organ Systems }\end{array}$ & 384 & 0,7298 & 0,7385 & 0,7113 & 0,9834 & 0,9859 & 0,9831 & 1,0842 & 1,0966 & 1,0946 & 1,0889 \\
\hline $\begin{array}{c}\text { Single Dominant or Moderate Chronic } \\
\text { Disease }\end{array}$ & 4216 & 0,6238 & 0,6237 & 0,5987 & 0,9408 & 0,9408 & 0,9382 & 0,9715 & 0,9687 & 0,9680 & 0,9660 \\
\hline $\begin{array}{c}\text { Disease in Chronic Multiple Organ } \\
\text { Systems }\end{array}$ & 1670 & 0,5011 & 0,5007 & 0,4815 & 0,9883 & 0,9881 & 0,9866 & 1,0719 & 1,0652 & 1,0645 & 1,0652 \\
\hline $\begin{array}{l}\text { Dominant Chronic Disease in Three } \\
\text { or More Organ Systems }\end{array}$ & 124 & 0,3671 & 0,3654 & 0,3468 & 1,0893 & 1,0883 & 1,0866 & 0,8724 & 0,8720 & 0,8724 & 0,8716 \\
\hline $\begin{array}{c}\text { Dominant and Metastatic } \\
\text { Malignancies }\end{array}$ & 178 & 0,5928 & 0,5904 & 0,5688 & 1,6095 & 1,6084 & 1,6055 & 1,2609 & 1,2732 & 1,2721 & 1,2719 \\
\hline Catastrophic Conditions & 66 & 0,0469 & 0,0464 & 0,0484 & 0,9386 & 0,9383 & 0,9394 & 1,2283 & 1,2326 & 1,2329 & 1,2334 \\
\hline male $0-14$ & 2789 & 2,1409 & 1,4123 & 0,9084 & 1,1120 & 0,9313 & 0,9535 & 4,4299 & 1,8389 & 1,1444 & 1,1302 \\
\hline male $15-29$ & 4511 & 1,2164 & 0,8611 & 0,9084 & 1,1108 & 1,0234 & 0,9955 & 2,5822 & 1,2296 & 0,8738 & 0,8737 \\
\hline male $30-44$ & 5216 & 0,9183 & 0,9565 & 1,2061 & 1,0524 & 1,0624 & 1,1136 & 1,5405 & 0,9644 & 0,9695 & 1,1005 \\
\hline male $45-64$ & 4626 & 1,1251 & 1,1934 & 1,0654 & 1,0453 & 1,0632 & 1,0400 & 0,9095 & 1,0761 & 1,1385 & 1,0756 \\
\hline male $65-79$ & 2926 & 0,9888 & 1,0011 & 1,0546 & 0,9825 & 0,9877 & 1,0028 & 0,6951 & 1,0065 & 1,0301 & 1,0556 \\
\hline male +80 & 1788 & 1,0260 & 1,0120 & 0,9843 & 1,0062 & 1,0088 & 0,9900 & 0,6499 & 0,9842 & 0,9812 & 0,9633 \\
\hline female $0-14$ & 3087 & 0,8849 & 1,7384 & 0,9199 & 0,7965 & 1,0131 & 1,0008 & 3,7238 & 0,9634 & 1,4746 & 0,8931 \\
\hline female $15-29$ & 4549 & 0,4066 & 0,5968 & 0,6523 & 0,8137 & 0,8593 & 0,9192 & 1,5947 & 0,3798 & 0,6024 & 0,7179 \\
\hline female $30-44$ & 5655 & 0,6953 & 0,6509 & 0,9284 & 1,0652 & 1,0519 & 1,0367 & 1,6641 & 0,7886 & 0,7882 & 0,9189 \\
\hline female $45-64$ & 4829 & 1,2454 & 1,1708 & 0,9962 & 1,0838 & 1,0651 & 1,0450 & 1,1164 & 1,2080 & 1,1300 & 1,0246 \\
\hline female $65-79$ & 2736 & 0,8864 & 0,8727 & 0,9139 & 0,9654 & 0,9597 & 0,9842 & 0,6779 & 0,9292 & 0,9044 & 0,9355 \\
\hline female +80 & 1067 & 0,9466 & 0,9639 & 0,9436 & 1,0103 & 1,0055 & 0,9551 & 0,7390 & 1,0172 & 1,0211 & 0,9972 \\
\hline
\end{tabular}

